\title{
Haberleşme Uydusu Güneş Algılayıcısının Isıl Kontrolü
}

\author{
${ }^{1}$ Murat Bulut ${ }^{2,3}$ Nedim Sözbir and ${ }^{4}$ Şenol Gülgönül \\ ${ }^{1}$ TÜRKSAT AŞ, Uydu Programlar Direktörlüğü, Gölbaşı, Ankara, Türkiye \\ *22Mühendislik Fakültesi, Makina Mühendisliği Bölümü, Sakarya Üniversitesi, Sakarya, Türkiye \\ ${ }^{3}$ TÜRKSAT AŞ, Ar-Ge ve Uydu Tasarım Direktörlüğü, Gölbaşı, Ankara, Türkiye \\ ${ }^{4}$ Electronic Control Department, BMC Power Motor ve Kontrol Sistemleri, Istanbul, 34906, Turkey
}

\begin{abstract}
Özet
Güneş algılayıcılar haberleşme uydularında yörünge ve yönelim altsisteminin en önemli ekipmanlarından biri olup uyduların dış kısmında uzaya bakan yüzeylerde yer alan ekipmanlardan biridir. Gerek uydu içinde gerekse uydu dışında yer alan her bir ekipman gibi güneş algılayıcılarda 1Sı yayınımı olmasa da 1 sıl analizlerin yapılması gerekmektedir. Bu çalışmada, yere duran uydularda yer alan ve yörünge ve yönelim altsistemine ait olan güneş algılayıcı ekipmanının 1sıl analizleri üzerinde çalışmalar yapılmıştır. Isıl analiz için güneş algılayıcı 1sı yayınımı değeri $0 \mathrm{~W}$, güneşten gelen 1S1 akısının değeri $1418 \mathrm{~W} / \mathrm{m}^{2}$ olarak alınmıştır. Güneş algılayıcının uydunun Dünyaya bakan yüzeyin tam tersi olan yüzeyde olduğu kabul edilmiştir. Isıl analizler en sıcak ve en soğuk durumlara göre yapılmıştır. Yapılan analiz sonucunda en sıcak ve en soğuk durumdaki sıcaklıkların kalifiye sıcaklıklar arasında kaldığ̣ görülmüştür.
\end{abstract}

Anahtar kelimeler: Güneş algılayıc1, haberleşme uydusu, 1sıl analiz

\section{Giriş}

Haberleşme uyduları ekvator üzerinden yeryüzüne göre değişmeyen yaklaşık 36,000 km uzakta yörünge de yer almaktadır. Haberleşme uyduları fonksiyonel olarak faydalı yük ve platform olarak iki ana yapıdan oluşmaktadır. Haberleşme alt sistemi, anten, telemetri ve komut, konumlama alt sistemleri faydalı yük sistemini oluşturmaktadır. Platform sistemi, tahrik, uçuş elektroniği, güç sistemi, yapısal alt sistemi ve 1sıl kontrol alt sisteminden oluşmaktadır. Şekil 1'de 3 eksenli stabilize haberleşme uydusu görülmektedir.

*Corresponding author: Address: Faculty of Engineering, Department of Mechanical Engineering Sakarya University, 54187, Sakarya TURKEY. E-mail address: sozbir@ sakarya.edu.tr, Phone: +902642955688 


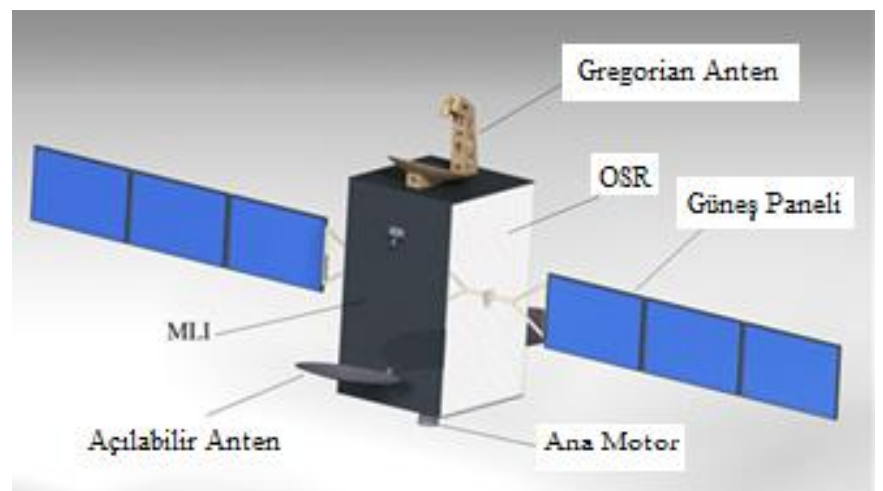

Şekil 1. Haberleşme uydusu [1]

Konum belirleme ve kontrol amaçlı kullanılan optik sensörler yıldız izler ve güneş sensörlerdir Güneş algılayıcısı diğer bir ifade ile güneş sensörü uzay aracının güneşin konumunu tespit etmek için kullanılan cihazlardır. Güneş algılayıcısı uydularda yörünge ve yönelim altsistemin ekipmanlarından biridir. Şekil 2'de iki farklı üretici tarafından üretilen güneş algılayıcıları görülmektektedir.

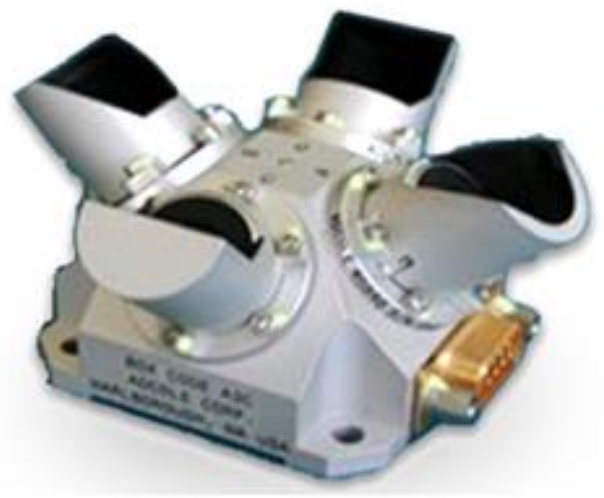

(a)

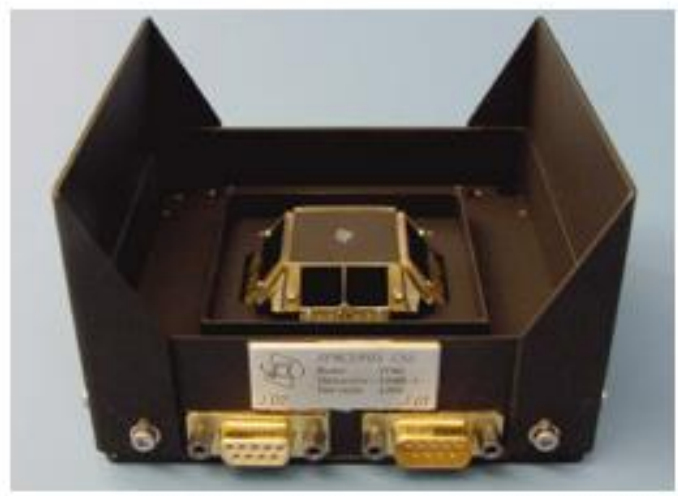

(b)

Şekil 2. Güneş algılayıcısı (a) Adcole corporation (b) TNO [2, 3] (telif hakkı Adcole Corp. ve TNO)

Güneş algılayıcılar uydunun dış kısmında yer aldığı için ve zorlu 1sıl şartlarına maruz kaldığ için özel 1sıl tasarımı ve analizi yapılmaktadır. Isıl algılayıcıların 1sıl kontrolünün sağlanması için radyatör alanlarına ve ısıtıcılara ihtiyaç duymaktadır.

\section{Güneş Algılayıcısı Isıl Kontrolü}

Güneş aygılayıcılar, uyduların dış kısmında yer alıp Dünya'ya bakan uydu yüzeyinin tam ters yüzeyinde yer alıp kendine özgü 1sl kontrol sistemine sahiptir. Güneş algılayıcılarda 1sıl kontrol olarak pasif donanımlardan, çok katmanlı yalıtım battaniyesi(ÇKYB), siyah boya ve 1sıl iletimin sağlanması için ara yüz malzeme kullanılmaktadır. Isıl aktif donanım olarak 1sıtıcılar ve 
termistörler kullanılmaktadır. Şekil 3'de güneş algılayıcı 1sıl kontrülü görülmektedir.

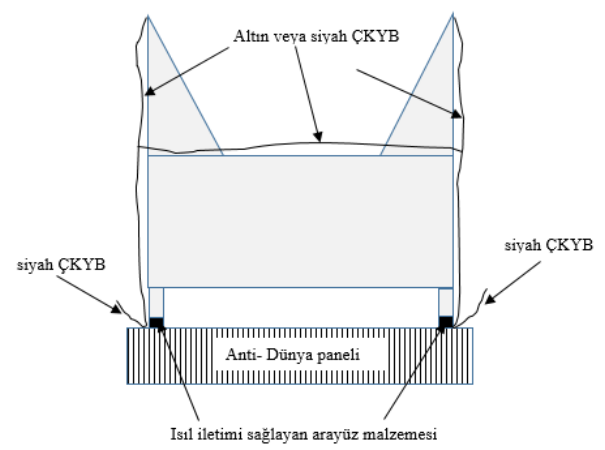

Şekil 3. Güneş algılayııı 1sıl kontrolü

\section{Güneş Algılayıcı Isıl Model Analizi}

Uydu gerek uydu içerisinde gerekse uydu dışında yer alan her bir ekipmanın, maruz kalacağı dışardan gelen 1sı akıları, uydunun yörüngedeki konumuna göre değişim göstermektedir. Isıl akıları, yaz dönümü, kış dönümü ve ekinaks duruma bağlı olarak değişmektedir. Ekipmanın maruz kalacağ1 1sı akıları, ekipmanın üreteceği 1s1 akısı, iletim ve 1şınım değerleri, yüzey soğurma ve yayınma değerlerinin bilinmesi ile birlikte ekipmanın sıcaklıkları hesaplanmaktadır.

Her bir eleman için 1sı dengesi, elemanın içindeki ve dışındaki her yönden ısı akışını analiz etmeye dayanır. Bu yöntem kontrol hacmi yaklaşımına benzer. Isı dengesi için diferansiyel denklem eşiklik 1'de verilmektedir. Şekil 4' de uzay ortamnda yer alan uyduya ait enerji dengesi görülmektedir.

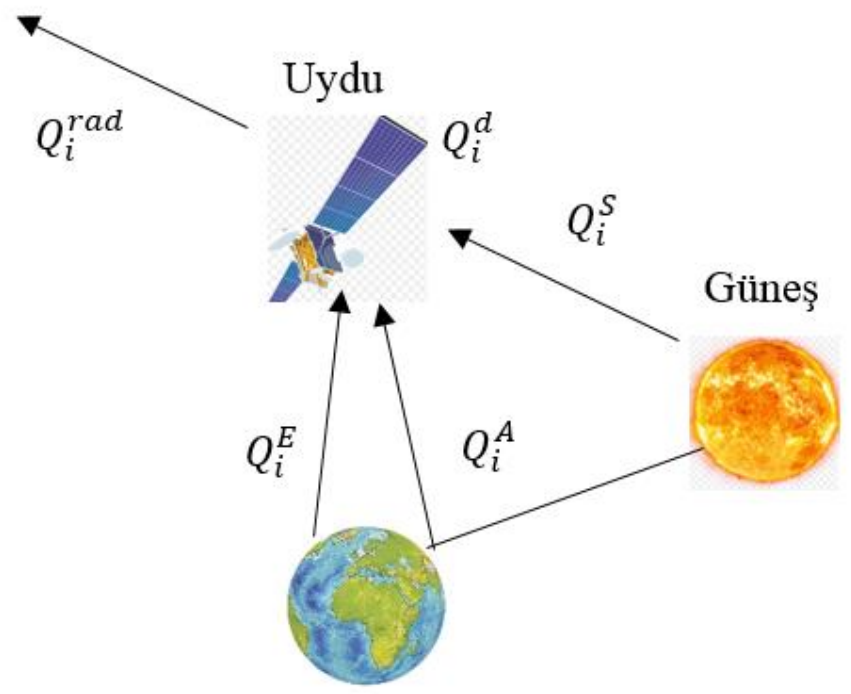

Dünya

Şekil 4. Uydularda enerji dengesi 
$Q_{i}^{d}+Q_{i}^{A}+Q_{i}^{E}+Q_{i}^{S}-Q_{i}^{r a d}=\frac{d E}{d t}$

Burada, $Q_{i}^{d}$, elektronik elemena gelen 1sıy1, $Q_{i}^{A}$, albedo 1sısın1, $Q_{i}^{E}$, dünyayan gelen 1sıy1, $Q_{i}^{S}$, güneşten uyduya gelen 1 sıyı gösterir. $Q_{i}^{\text {rad }}$, uydu elektronik elemanından radyatör alanına 1sı iletimi ile radyatör alanından uzaya radyasyonla atılan 1sıyı gösterir.

Uydularda yer alan herbir ekipman sıcaklığı enerji denge denklemi çözümü ile elde edilmektedir. Uyduda yer alan her bir eleman için enerji denklemi eşitlik 2' de olduğu gibi uygulanmaktadır..

$$
(M c)_{i} \frac{d T_{i}}{d t}=Q_{i}{ }^{d}+\left(\alpha^{s} A^{s} q^{s}+\alpha^{s} A^{A} q^{A}+\varepsilon A^{E} q^{E}\right)_{i}-\sum_{j} \mathfrak{I}_{i j} A_{i}^{r}\left(\sigma T_{i}^{4}-\sigma T_{j r}^{4}\right)-\sum_{j} K_{i j}\left(T_{i}-T_{j k}\right)
$$

Denklemin en sol kısmında yer alan ifade uydu elamanının 1sıl kapasitansını ifade etmektedir. Eşitliğin sağ tarafında yer alan ilk ifade uydu elemanının isıl yük değerini, ikinci terim net soğurulan 1sıyı, üçüncü terim ışınım ile uzaya atılan 1sıyı ve en son terim de iç iletimini ifade etmektedir [4].

Sicak ve soğuk durum için analizler yapılmaktadır. Analizlerde $1418 \mathrm{~W} / \mathrm{m}^{2}$ 1Sı akısı en yükesk olarak alınmış ve güneş algılayıcının üretmiş olduğu 1sı akısı değeri 0 olarak alınmıştır. Güneş algılayıcı kütlesi $0.4 \mathrm{~kg}$ ve fiziksel boyutları olarak $129 \mathrm{~mm}$ x $120 \mathrm{~mm}$ x $73 \mathrm{~mm}$ olarak alınmıştır. Bu çalışmada Şekil 2 (b)' de yer alan TNO üretici firmasına ait güneş algılayıcı örnek olarak alınmıştır. Isı yayınım $(\varepsilon)$ ve soğurma katsayısı $(\alpha)$ olarak altın renkli ÇKYB için 0.61 ve 0.35 olarak alınmıştır. Siyah ÇKYB için ısı yayınım $(\varepsilon)$ ve soğurma katsayısı $(\alpha)$ olarak 0.84 ve 0.93 olarak alınmıştır. Uzay sıcaklığı 4K olarak alınmıştır. Şekil 5'de güneş algılayıcısına ait nodeler görülmektedir. 2,3,4 ve 5 numaralı nodlar hücre çiftlerini göstermektedir. 


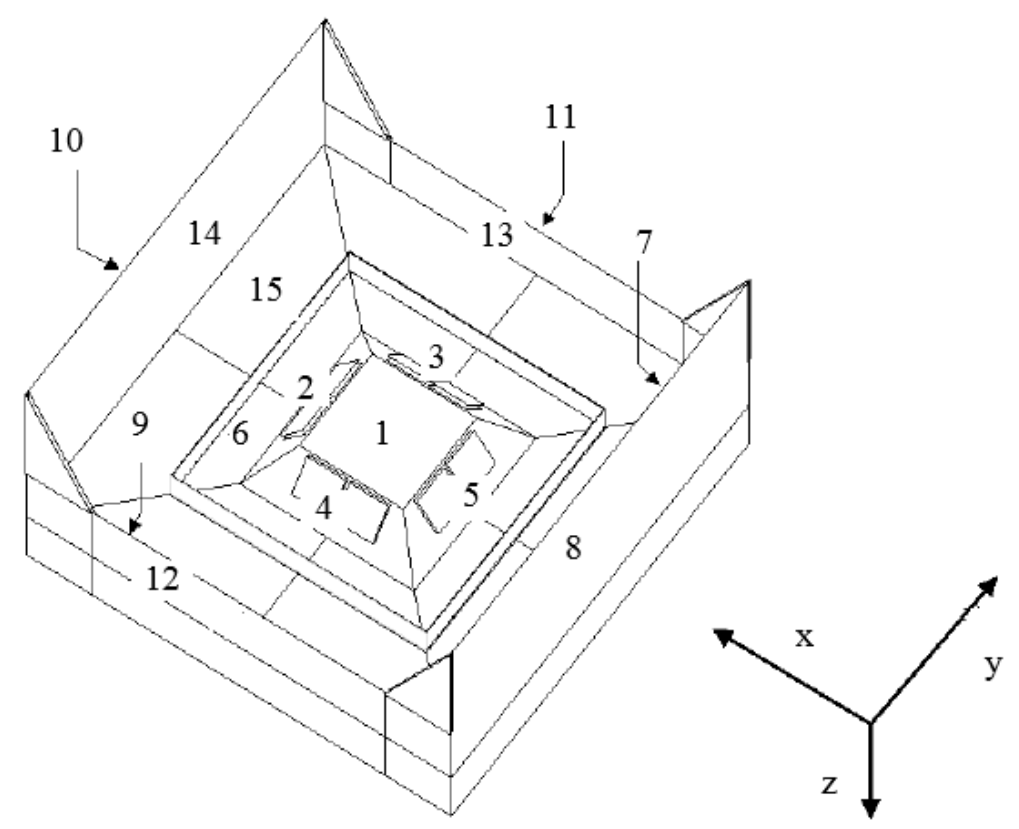

Şekil 5. Güneş algılayıcı nodları

\section{Isıl Analiz Sonuçları}

Güneş algılayıcısı 1sıl kontrolülnde sıcak ve soğuk durum gözönüne alınarak analizler yapılmıştır. Analiz sonuçları Tablo 1'de yer almaktadır. En kötü sıcak durum 1418 W/m² 1 sı akısı ile elde edilirken en kötü soğuk durum $0 \mathrm{~W} / \mathrm{m}^{2} 1 \mathrm{~s} 1$ akısı ile elde edilmiştir. En kötü sıcak durum için ortalama hesaplanan analiz sıcaklık sonucu $99^{\circ} \mathrm{C}$ iken en kötü soğuk durum için ortalama analiz sicaklık sonucu $-28{ }^{\circ} \mathrm{C}$ olarak hesaplanmıştır.

Tablo 1. Güneş Algılayıcı min. ve max. sıcaklıkları

\begin{tabular}{|c|c|c|c|c|}
\hline & \multirow[b]{3}{*}{ Node } & \multirow[t]{2}{*}{ Hesaplanan sicaklıklar } & \multicolumn{2}{|c|}{ Kalifiye sıcaklıklar } \\
\hline & & & Operasyonel & Operasyonel olmayan \\
\hline & & ${ }^{\circ} \mathrm{C}$ & ${ }^{\circ} \mathrm{C}$ & ${ }^{\circ} \mathrm{C}$ \\
\hline \multirow[t]{4}{*}{ En kötü sıcak durum } & 2 & 100.05 & +120 & +120 \\
\hline & 3 & 98.28 & & \\
\hline & 4 & 98.29 & & \\
\hline & 5 & 100.05 & & \\
\hline \multirow[t]{4}{*}{ En kötü soğuk durum } & 2 & -28.23 & -60 & -70 \\
\hline & 3 & -28.48 & & \\
\hline & 4 & -28.48 & & \\
\hline & 5 & -28.25 & & \\
\hline
\end{tabular}




\section{Sonuçlar}

Isıl kontrol alt sistemi, ekipmanların çalışma sıcaklık aralıklarında çalışması için gerekli olan şartları sağlaması ana görevidir. Bu çalışmada, güneş algılayıcıları için 1sıl kontrol alt sistemi olarak ısıl tasarım ve analizler yapılmıştır. Isıl analiz sonucunda hesaplanan sıcaklık değerlerinin kalifiye sıcaklık değerleri içerisinde kaldığ 1 görülmüştür.

\section{Kaynak}

[1] Bulut M, Sözbir N. Prediction of the solar array temperatures of geostationary earth orbit satellite by using analytical methods. 9th International Conference on Recent Advances in Space Technologies-RAST 2019, Turkish Airforce Academy, Istanbul, 11-14 June 2019.

[2] https://www.adcole.com

[3] https://www.tno.nl

[4] Megahed A, El-Dib A. Thermal design and analysis for battery module for a remote sensing satellite. Journal of Spacecraft and Rockets 2007; 44 (4):920-926. 